\title{
SISTEM PENCARIAN PROGRAM STUDI PADA PERGURUAN TINGGI DI BALI BERBASIS SEMANTIK
}

\author{
${ }^{1}$ Kadek Dwi Pradnyani Novianti, ${ }^{2}$ Ricky Aurelius Nurtanto Diaz \\ 1, 2 Program Studi Sistem Komputer, STMIK STIKOM Bali \\ Denpasar, Indonesia \\ e-mail: 1novianti@stikom-bali.ac.id,_2ricky@stikom-bali.ac.id
}

\begin{abstract}
Abstrak
Pendidikan di Indonesia khususnya di Bali berlangsung secara berjenjang, dimulai dari pendidikan dasar sampai dengan pendidikan tinggi. Pendidikan tinggi diselenggarakan oleh berbagai satuan penyelenggara, seperti Akademi, Sekolah Tinggi, Institut, dan Universitas. Calon mahasiswa sebelum menentukan pilihan program studi dari sebuah perguruan tinggi harus melakukan pencarian informasi berkaitan dengan program studi. Pencarian informasi dapat diselesaikan dengan membangun sebuah sistem pencarian berbasis semantik. Ontologi menjadi dasar dari penerapan web semantik karena dapat merepresentasikan konten menjadi basis pengetahuan yang dapat dipahami oleh mesin. Sistem ini bertujuan untuk membantu calon mahasiswa untuk mendapatkan deskripsi informasi program studi yang diinginkan. Tahapan pengujian sistem, diperoleh hasil nilai recall sebesar 0.95 dan nilai precision sebesar 0.93, menunjukan bahwa sistem memiliki tingkat relevansi dan ketepatan pengembalian informasi yang tinggi. Selanjutnya diharapkan bahwa sistem ini mampu mengakomodasi detail informasi program studi seluruh perguruan tinggi di Indonesia.
\end{abstract}

Kata kunci: web semantik, ontologi, program studi, recall, precision

\begin{abstract}
Education in Indonesia especially Bali implemented hierarchical, starting from basic up to higher education. Higher education organized by the various units, such as Akademi, Sekolah Tinggi, Institutes, and Universities. Student candidates before determining the choice of courses from college can search information related to the course. Searching information can be completed with the semantic search system. Ontology is the basis of the semantic web which can represent the content into knowledge base, Purpose of the system helps student candidates to get a description about the course in college. At system testing, the results obtained recall value of 0.95 and precision value of 0.93 , which indicates that the system has a high level of relevance and accuracy in information returns. Furthermore, it is expected that the system is able to accommodate the detail information of courses from all colleges in Indonesia.
\end{abstract}

Keywords : semantic web, ontology, course, recall, precision 


\section{PENDAHULUAN}

Pendidikan merupakan faktor utama pembentuk pribadi manusia. Pendidikan sangat berperan untuk membentuk baik atau buruknya pribadi manusia menurut ukuran normatif. Budaya pendidikan Indonesia yang berjalan selama ini dilakukan secara berjenjang. Berjenjang yang dimaksud adalah dimulai dari pendidikan tingkat usia dini, pendidikan tingkat dasar, pendidikan tingkat menengah dan pendidikan tingkat tinggi. Perbandingan yang terjadi adalah semakin tinggi seseorang menempuh tingkat pendidikan maka akan dianggap semakin meningkat pula produktivitas orang tersebut. Pengetahuan yang diperoleh selama proses menempuh pendidikan tersebut dapat digunakan sebagai pedoman untuk menciptakan pembaharuan-pembaharuan dalam berbagai bidang dan aspek kehidupan masyarakat (Atmanti, 2005).

Satuan penyelenggara pendidikan tinggi di Indonesia antara lain akademi, institut, sekolah tinggi, politeknik dan universitas menjadi alternatif lembaga pendidikan bagi calon mahasiswa. Biasanya sebuah lembaga penyelenggara pendidikan terdiri dai program-program studi tertentu sebagai bagian dari lembaga tersebut. Seorang calon mahasiswa biasanya dihadapkan pada pilihan untuk memilih program studi yang diinginkannya dan mempertimbangkan reputasi program studi serta perguruan tinggi pilihannya. Proses pemilihan program studi yang akan ditekuni menjadi salah satu hal yang penting yang harus diperhatikan oleh seorang calon mahasiswa karena program studi menjadi bidang keahlian yang akan ditekuni oleh calon mahasiswa di masa depan kelak.

Banyaknya perguruan tinggi yang tersebar di suatu daerah di Indonesia khususnya di Provinsi Bali dan program studi yang dimiliki sangatlah beragam. Banyak pertimbangan seperti reputasi program studi, akreditasi perguruan tinggi dan lokasi yang harus dihadapi oleh seorang calon mahasiswa. Permasalahan ini memerlukan sebuah solusi berupa informasi program studi tertentu bagi calon mahasiswa untuk dapat mendukung pilihan program studi yang akan dipilinnya dari sebuah perguruan tinggi.

Mesin pencari informasi terkait program studi dari sebuah perguruan tinggi dapat menjadi solusi untuk menyelesaikan permasalahan yang ada. Pemanfataan teknologi berupa mesin pencari berbasis semantik yang mampu menampilkan hasil deskripsi informasi mengenai program studi sangat diperlukan untuk mengatasi masalah yang ada. Teknologi web semantik mampu memahami makna kata kunci yang diinputkan oleh pengguna ke dalam mesin pencari, sehingga ada kesamaan makna antara pengguna dan mesin pencari. Inti dari web semantik adalah mengaplikasikan ontologi untuk merepresentasikan konten atau informasi menjadi basis pengetahuan dalam bentuk-bentuk yang dapat dipahami dan diproses oleh mesin (Jhon Davies, Fensel, \& Harmelen, 2003). Ontologi dapat digunakan untuk mengekspresikan informasi program studi secara eksplisit dan semantik. Penerapan ontologi akan dapat memfasilitasi mesin untuk memahami dan memproses informasi secara otomatis, dan kemudian membantu sistem agar dapat memberikan layanan yang baik kepada penggunanya (Changping \& Yang, 2007).

Berdasarkan permasalahan di atas, dapat disimpulkan bahwa akan dibangun sebuah sistem pencarian untuk memfasilitasi permasalahan pemilihan program studi sebagai bahan pertimbangan

Jurnal Sains dan Teknologi | 94 
calon mahasiswa menempuh jejang pendidikannya. Mesin pencari ini akan dibuat dengan pemanfaatan teknologi web semantik dan data program studi akan disimpan dalam sebuah metadata berbasis ontologi agar dapat memiliki basis pengetahuan dalam bentuk yang dapat dipahami oleh mesin. Penelitian ini diharapkan mampu memfasilitasi calon mahasiswa dalam melakukan pemilihan program studi yang diinginkan.

\section{STATE OF THE ART}

Davies (John Davies, Fensel, \& van Harmelen, 2003) menyatakan bahwa teknologi web semantik mampu memberikan pemahaman makna kata yang sama baik oleh manusia maupun mesin. Web semantik berkaitan dengan penerapan ontologi untuk merepresentasikan konten atau informasi menjadi basis pengetahuan dalam bentuk-bentuk yang dapat dipahami dan diproses oleh mesin. Penerapan ontologi untuk merepresentasikan informasi kemudian dapat digunakan untuk mengatasi permasalahan yang terjadi pada sistem temu kembali informasi (Wu-jun \& Peng, 2010). Sistem temu kembali informasi yang masih tradisional memiliki sedikit kemampuan untuk inferensi secara semantik. Selain itu, nilai recall dan precision-nya tidak dapat memenuhi kebutuhan pengguna. Hasil yang diperoleh pada penelitian ini adalah ontologi mampu merepresentasikan informasi dokumennya dengan baik dan dapat memberikan deskripsi informasi secara semantik. Selain itu, hasil sistem temu kembali informasi diperoleh peningkatan nilai recall dan precision sehingga mampu memenuhi kebutuhan pengguna.

Mehta membangun sebuah mesin pencari yang dimodifikasi dengan menambahkan konsep ekstraksi kata kunci dan perhitungan keterkaitan semantik antar kata-kata (Mehta, Makkar, Palande, \& Wankhede, 2015). Pada penelitian tersebut, mesin pencari memiliki tujuan utama untuk memecahkan query pencarian dengan hasil yang tepat dan dalam waktu yang singkat serta dengan algoritma tertentu. Web semantik dapat membantu penemuan, otomatisasi, integrasi, dan penggunaan kembali data yang lebih efisien dan mendukung masalah interoperabilitas yang tidak dapat diselesaikan oleh teknologi web saat ini. Pada penelitian ini dilakukan menggunakan 25 dataset yang berkaitan dengan makanan dan binatang. Hasil yang diperoleh menunjukan bahwa mesin pencari yang dibangun tidak hanya menghasilkan informasi yang berkaitan dengan kata kunci tersebut tepati juga yang berkaitan dengan kata kunci. Selain itu juga kualitas dan efisiensi mesin pencari berbasis semantik meningkat dengan pesat.

Sistem temu kembali informasi atau mesin pencari tradisional tidak memiliki hubungan dengan domain pengetahuan manapun, sehingga mesin pencari tidak memahami makna kata kunci dari pengguna dan bagaimana hubungan yang melekat antar terms pada dokumen web. $\mathrm{Hal}$ ini menyebabkan kemampuan untuk melakukan penelusuran terbatas berdasar pada pencocokan kata kunci. Mesin pencari tradisional melakukan pencocokan query terms terhadap kata kunci pada indeks, akan mengalami kegagalan untuk menghasilkan informasi yang relevan ketika kata kunci yang digunakan pada query berbeda dengan yang digunakan pada indeks, walaupun memiliki makna yang sama. Maka dalam penelitian dibangun

Jurnal Sains dan Teknologi | 95 
sebuah sistem pencarian berbasis semantik dengan mengambil objek penelitian pencarian informasi program studi bagi calon mahasiswa. Dimana web semantik ini akan menerapkan ontologi sebagai representasi informasi program studi, dengan mengambil sampel sebanyak 30 perguran tinggi yang ada di Bali. Dengan sistem ini diharapkan calon mahasiswa mendapatkan informasi program studi yang diinginkan sebelum memilihnya.

\section{WEB SEMANTIK}

Kata semantik berarti makna atau sesuatu yang berhubungan dengan ilmu yang mempelajari makna dan perubahan makna. Berners-Lee, dkk menyebutkan bahwa makna dari suatu data yang terdapat dalam web dapat dipahami bukan hanya oleh manusia namun juga oleh mesin (machine understandable) (Berners-lee, Hendler, \& Lassila, 2001; Shadbolt, Hall, \& Berners-Lee, 2006). Web semantik merupakan generasi web selanjutnya yang memiliki tujuan untuk otomasi, integrasi, dan penggunaan kembali data pada aplikasi web yang berbeda. Web semantik adalah perluasan dari World Wide Web dengan teknik baru dan standar terhadap interoperation dan pemahaman oleh komputer. Web memiliki jumlah data yang besar, tapi jika hanya mengandalkan kemampuan komputer saja, tentunya komputer tidak bisa memahami atau membuat keputusan tentang data yang dimilikinya, sehingga diperlukan web semantik untuk menyelesaikannya. Web semantik diperlukan untuk mengekspresikan informasi yang tepat sehingga software agent dapat memproses seperangkat data yang sama untuk membagikan sebuah pemahan tentang istilah yang mendeskripsikan maksud data.
Berners-Lee membangun berbagai infrastruktur untuk keperluan data yang bisa lebih dipahami mesin (Berners-lee et al., 2001; Shadbolt et al., 2006). Beberapa komponen yang telah dibangun diantaranya adalah RDF (Resource Description Framework) serta OWL (Ontology Web Language). Komponen utama web semantik seperti pada Gambar 1 , didasarkan pada komponen lainnya yang telah dibangun oleh W3C (World Wide Web Consortium) yaitu XML (Extensible Markup Language), URI (Uniform Resource Identifier), maupun HTTP (Hypertext Transfer Protocol).
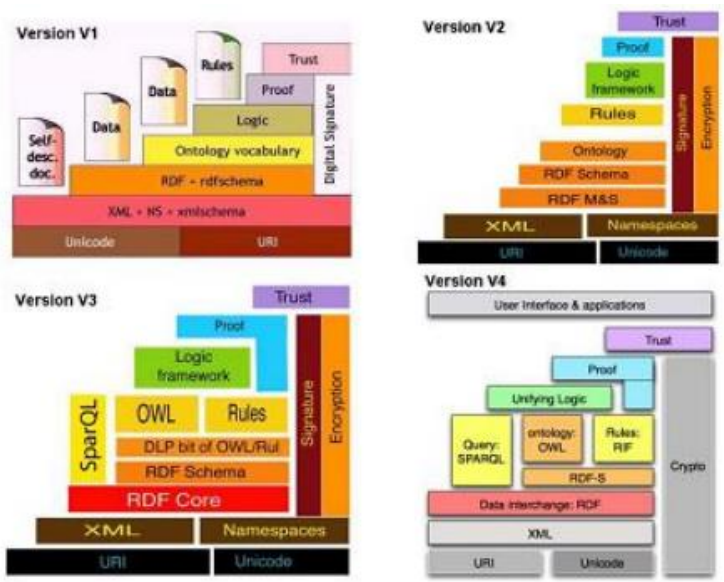

Gambar 1. Pengembangan Layer Web Semantik (Gerber, Van Der Merwe, \& Barnard, 2008)

\section{ONTOLOGI}

Dalam literatur kecerdasan buatan banyak yang mendefinisikan ontologi dalam berbagai pandangan. Ontologi sebelumnya merupakan konsep filosofi. Dalam bidang kecerdasan buatan dan web, ontologi menggambarkan konsep domain dan hubungannya. Ontologi menjelaskan bagaimana teori tentang suatu objek dan keterkaitan diantara mereka 
(Chandrasekaran, Josephson, \& Benjamins, 1999).

Ontologi menjadi elemen penting dalam banyak aplikasi, dimana dapat digunakan dalam system agent, knowledge management systems, dan e-commerce platforms. Ontologi juga dapat mengenerate bahasa alami, mengintegrasikan intelligent information, menyediakan akses berbasis semantik, dan mengekstrak informasi dari teks. Disamping itu juga, ontologi dapat digunakan dalam berbagai aplikasi lainnya yang secara eksplisit memiliki pengetahuan yang tertanam didalamnya (Gómez-Pérez, FernándezLópez, \& Corcho, 2003).

Noy dan McGuinness (N. Noy \& McGuinness, 2001) mendefinisikan bahwa ontologi adalah sebuah deskripsi formal yang eksplisit dari konsep dalam sebuah domain yang terdiri dari classes (kadang disebut sebagai konsep), properti dari masing-masing konsep yang mendeskripsikan berbagai fitur dan atribut dari konsep disebut slot (juga disebut sebagai roles atau properti), dan pembatasan pada slot yang disebut facets (role restrictions).

Terdapat beberapa tujuan untuk mengembangkan ontologi yang dijelaskan sebagai berikut.

a. Berbagi pemahaman umum dari struktur informasi antar pengguna atau software agent.

b. Memungkinkan kembali penggunaan domain pengetahuan.

c. Membuat asumsi domain yang eksplisit.

d. Memisahkan domain pengetahuan dari operasional pengetahuan.

e. Menganalisis domain pengetahuan. Secara teknis, ontologi direpresentasikan dalam bentuk class, properti, slot dan instance seperti yang telah didefinisikan sebelumnya bahwa ontologi merupakan deskripsi eksplisit dari konsep domain pengetahuan. Representasi ontologi dijabarkan sebagai berikut beserta contoh penggambaran representasi ontologi pada Gambar 2.

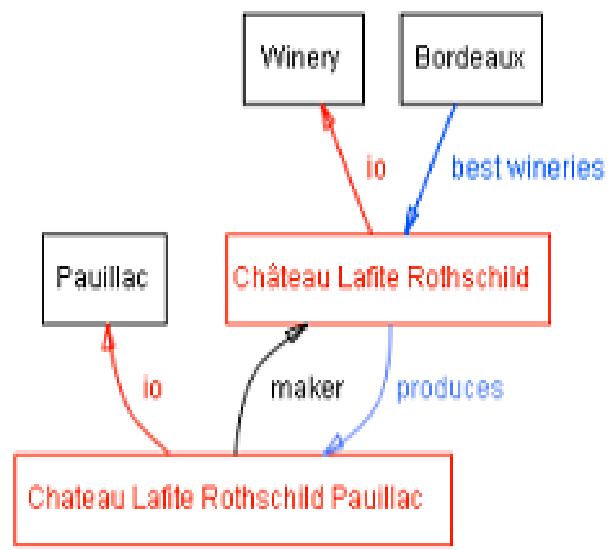

Gambar 2. Contoh ontologi pada Domain Wine (N. F. Noy \& McGuinness, 2001)

\section{ONTOLOGY WEB LANGUAGE (OWL)}

Ontology Web Language (OWL) merupakan suatu bahasa yang digunakan untuk mendeskripsikan class, property dan relasi antar objek dalam suatu cara yang dapat diinterpretasikan oleh mesin. OWL merupakan sebuah vocabulary namun dengan tingkatan semantik yang lebih tinggi dibandingkan dengan RDF dan RDF Schema (McGuinness \& Harmelen, 2003). OWL menyediakan tiga sub bahasa berbeda yang dirancang untuk berbagai kebutuhan tertentu dari pengguna yaitu sebagai berikut.

1. OWL Lite

OWL Lite menyediakan pendefinisian hirarki kelas dan properti dengan constraint yang sederhana. Jenis ini digunakan jika pengguna hanya

Jurnal Sains dan Teknologi | 97 
membutuhkan hirarki kelas yang sederhana pula.

2. OWL DL

OWL DL mendukung pengguna yang menginginkan ekspresi maksimum tanpa kehilangan perhitungan yang lengkap dan ketepatan. OWL DL meliputi semua bahasa konstruksi dalam OWL dengan batasan tertentu. OWL DL dapat menghasilkan hirarki klasifikasi secara otomatis dan mampu mengecek konsisten dalam suatu ontologi karena OWL DL mendukung reasoning.

3. OWL Full

OWL Full diperuntukan untuk pengguna yang menginginkan sub bahasa yang sangat ekspresif dengan kebebasan sintaksis dari RDF tanpa ada jaminan komputasional. Misalnya, dalam OWL Full, suatu kelas boleh dianggap sebagai kumpulan dari individu dan sekaligus menjadi individu bagi dirinya sendiri. OWL Full juga memungkinkan suatu ontologi merubah arti dari kosakata yang sudah didefinisikan, misalnya kosakata milik RDF. Hal ini yang menyebabkan OWL Full tidak mendukung reasoning yang lengkap.

Sintaks dan semantik formal dari OWL diperlukan untuk membuat ontologi dapat diinterpretasikan dan digunakan oleh perangkat lunak. OWL dibuat berdasarkan RDF dan RDF Schema yang berbasiskan XML. OWL menyediakan konsep untuk mendefinisikan class dengan menggunakan owl:Class. Setiap kelas dalam OWL merupakan sub kelas dari owl:Thing. Setiap kelas dalam OWL berhubungan dengan jumlah individu yang disebut perluasan kelas (class extention). Individu-individu dalam perluasan kelas disebut instance. Sebuah kelas juga memiliki konsep khusus yang dapat berelasi namun tidak sama dengan kelas yang menjadi perluasannya. Oleh karena itu, dua kelas mungkin memiliki perluasan kelas yang sama, namun tetap merupakan kelas yang berbeda. OWL membedakan properti ke dalam dua kategori yaitu :

1. Object Property, yang menghubungkan individu yang satu dengan yang lain. Properti ini didefinisikan sebagai instance dari kelas owl: Object Property.

2. Datatype Property, yang menghubungkan individu ke nilai data. Properti ini didefinisikan sebagai instance dari kelas owl : DatatypeProperty.

\section{METODOLOGI}

Pembangunan ontologi dilakukan melalui 2 tahapan yaitu konseptualisasi ontologi dan formalisasi ontologi. Tahapan konseptualisasi yang bertujuan untuk mengatur dan mengelola pengetahuan yang diperoleh selama proses akuisisi pengetahuan. Ketika model konseptual selesai dibangun, selanjutnya adalah mengubah model konseptual menjadi model formal, yang kemudian diimplementasikan dengan bahasa implementasi ontologi. Proses ini bergerak secara bertahap dari level pengetahuan ke level implementasi untuk meningkatkan derajat formalitas model pengetahuan secara perlahan sehingga dapat dipahami oleh mesin.

Perubahan dari level pengetahuan ke level implementasi dapat digambarkan pada Gambar 3. Transformasi T1 menunjukan proses model konseptual, ini merupakan trasformasi dari domain pengetahuan ke model konseptual yang

Jurnal Sains dan Teknologi | 98 
mendeskripsikan domain tersebut. Transformasi T2 mengkonversi model konseptual menjadi model formal. Transformasi T3 mentransformasikan model formal menjadi model yang dapat dieksekusi oleh komputer (Gómez-Pérez et al., 2003).

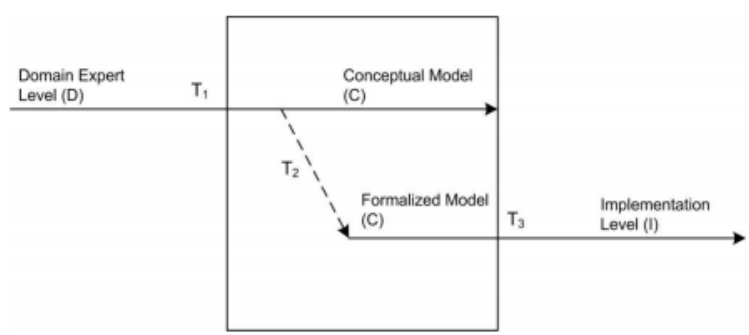

Gambar 3. Proses Pengembangan Ontologi (Gómez-Pérez et al., 2003)

\begin{abstract}
Pembangunan ontologi dilakukan menggunakan metodologi METHONTOLOGY. METHONTOLOGY merupakan sebuah metodologi yang dikembangkan oleh sebuah grup ontologi di Universidad Politécnica de Madrid. METHONTOLOGY memungkinkan pembangunan ontologi pada level pengetahuan. METHONTOLOGY terdiri dari proses pengembangan ontologi, kemampuan life cycle yang didasarkan pada pengembangan prototipe, dan teknikteknik untuk melaksanakan tiap aktivitas, orientasi pengembangan dan aktivitas pendukung lainnya .METHONTOLOGY memiliki kemampuan untuk melakukan life cycle ontologi berdasarkan pada pengembangan prototipe karena hal ini mengijinkan penambahan, perubahan, dan penghapusan terms pada tiap versi terbarunya (prototipe) (Gómez-Pérez et al., 2003).
\end{abstract}

\section{HASIL DAN PEMBAHASAN}

Proses pembangunan ontologi hanya dilakukan proses penambahan terms pada ontologi prodi yang telah ada (Novianti, 2016) untuk memenuhi kebutuhan sistem pencarian. Pembangunan ontologi dibangun menggunakan Protégé 4.3 dimana setelah ontologi selesai dibangun konsistensi ontologi diperiksa menggunakan Pellet Reasoner. Pellet (Abburu, 2012) merupakan sebuah tools reasoner untuk menguji konsistensi deskripsi logika yang telah didefinisikan. Pellet akan memberikan peringatan apabila terdapat deskripsi logika yang mengalami inkonsistensi.

Ontologi prodi mengalami penambahan datatype properties yaitu deskripsiPT, sehingga ontologi prodi memiliki 9 datatype properties. Datatype properties pada ontologi prodi dapat dilihat secara detail pada Gambar 4

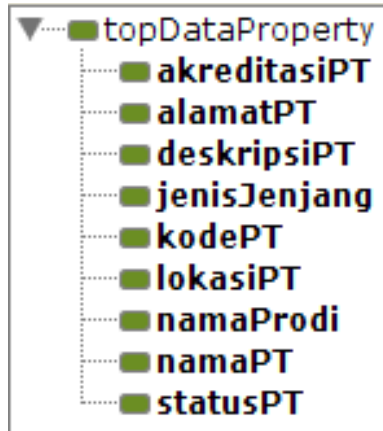

Gambar 4. Datatype properties ontologi prodi

Ontologi prodi memiliki 4 class yaitu Jenjang, Lokasi, Perguruantinggi, Programstudi. Dimana class PerguruanTinggi dibagi lagi menjadi beberapa subclass yaitu Akademi, Institut, Politeknik, Sekolahtinggi dan Universitas seperti pada Gambar 5.

Object properties merupakan komponen yang menghubungkan class pada sebuah ontologi. Object properties

Jurnal Sains dan Teknologi | 99 
yang ada pada ontologi prodi adalah has Jenjang, hasLokasi, hasProgramstudi, dan isProgramstudiof. Object properties pada ontologi prodi dapat dilihat pada Gambar 6.

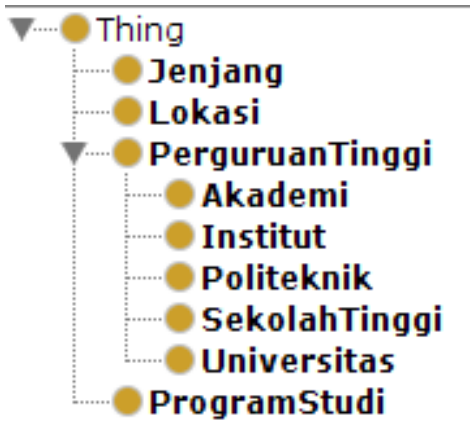

Gambar 5. Class ontologi prodi

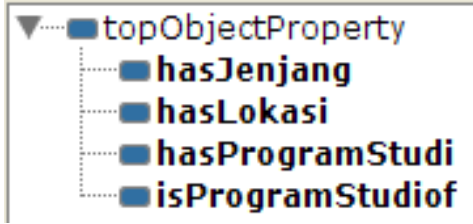

Gambar 6. Object properties Ontologi Prodi

Instance dalam Protégé didefinisikan sebagai individual. Contoh individual yang telah didefinisikan pada ontologi prodi dapat dilihat pada Gambar 7. Individual yang ditampilkan mewakili individual lokasi/wilayah tempat perguruan tinggi berada dan individual beberapa program studi yang dimiliki oleh beberapa perguruan tinggi dalam sampel.

Model formal yang dibangun menggunakan Protégé 4.3 diuji menggunakan Pellet Reasoner. Ontologi prodi yang dikembangkan mencapai hasil yang konsisten, diindikasikan dengan berjalannya proses reasoning pada Pellet dan tidak menghasilkan error sehingga mampu menghasilkan inferensi berupa fakta-fakta baru. Proses reasoning menghasilkan fakta-fakta baru berupa data instances baru, relasi baru, dan atribut baru. Model formal ontologi yang telah konsisten diimplementasikan ketika melakukan pembangunan sistem menggunakan Eclipse Kepler dan JENA API sebagai penghubung.

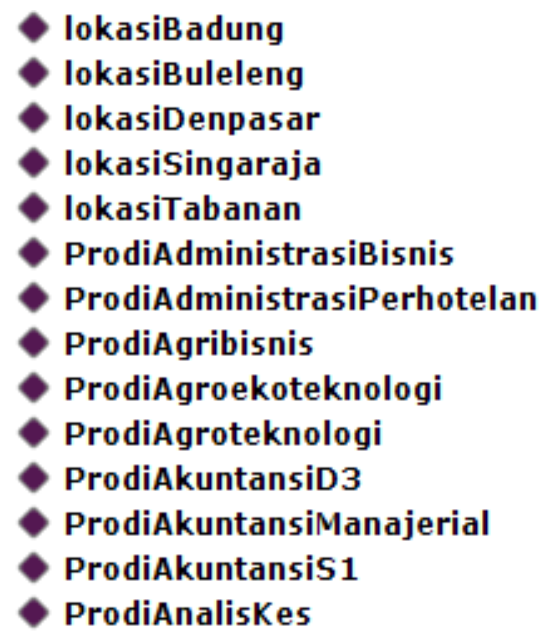

Gambar 7. Contoh Individual Ontologi Prodi

Tahapan setelah model formal dari ontologi terbentuk adalah pembangunan sistem. Pembangunan sistem merupakan tahapan untuk implementasi ontologi sebagai representasi informasi berbasis pengetahuan. Pembangunan sistem pencarian dilakukan menggunakan perangkat lunak Eclipse Kepler dan koneksi ke basis pengetahuan dilakukan menggunakan JENA API. Data sampel yang digunakan dalam penelitian ini diambil dari laman forlap.dikti.go.id. Data sampel berjumlah 30 buah data perguruan tinggi yang ada di Bali untuk semua jenis satuan penyelenggara pendidikan yang ada di Indonesia.

Sistem pencarian dibangun dengan sebuah fitur pencarian. Fitur ini memerlukan input berupa keyword program studi yang diinginkan oleh pengguna. Gambar 8

Jurnal Sains dan Teknologi | 100 
menunjukan halaman awal sistem pencarian, pada halaman inilah pengguna dapat memulai pencarian program studi yang diinginkan. Sistem menerima keyword yang diinputkan pengguna kemudian memproses query pencarian pada ontologi program studi dan memberikan hasil output berupa daftar informasi program studi yang diinginkan pengguna seperti pada Gambar 9. Informasi yang disampaikan merupakan informasi umum terkait program studi yaitu perguruan tinggi yang menaunginya, lokasi perguruan tinggi berada dan deskripsi program studi tersebut. Sistem dapat memberikan daftar informasi program studi tertentu lebih detail yang mencakup perguruan tinggi, lokasi, alamat, akreditasi, status dan deskripsi dari program studi yang diinginkan. Penggambaran detail daftar informasi program studi ditunjukkan pada Gambar 10. Hasil sistem menunjukan bahwa sistem sudah mampu mengembalikan informasi berdasarkan keyword pencarian yang diinputkan oleh pengguna. Tahapan akhir adalah tahapan pengujian untuk mengetahui relevansi sistem dalam mengembalikan informasi kepada pengguna. Pengujian dilakukan dengan menggunakan kata-kata kunci yang direpresentasikan di dalam ontologi untuk masing-masing perguruan tinggi, lalu berdasarkan kata kunci pengujian akan dihitung tingkat relevansi dari informasi yang diberikan oleh sistem.

Tahapan pengujian mengadospi tahapan pengujian sistem temu kembali informasi, yaitu penilaian recall dan precision (Wahyudi, 2013). Recall menggambarkan perolehan informasi oleh sistem dan precision menggambarkan ketepatan informasi relevan. Kedua penilaian ini merupakan parameter yang dapat digunakan untuk menyatakan relevansi dari sebuah sistem temu kembali informasi. Relevansi menggambarkan keefektifan proses temu kembali informasi, dimana sebuah sistem mampu memberikan informasi yang sesuai dengan persepsi pengguna.

\section{SISTEM INFORMASI}

PROGRAM STUDI DI PERGURUAN TNGG

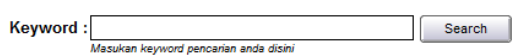

Gambar 8. Halaman Pencarian

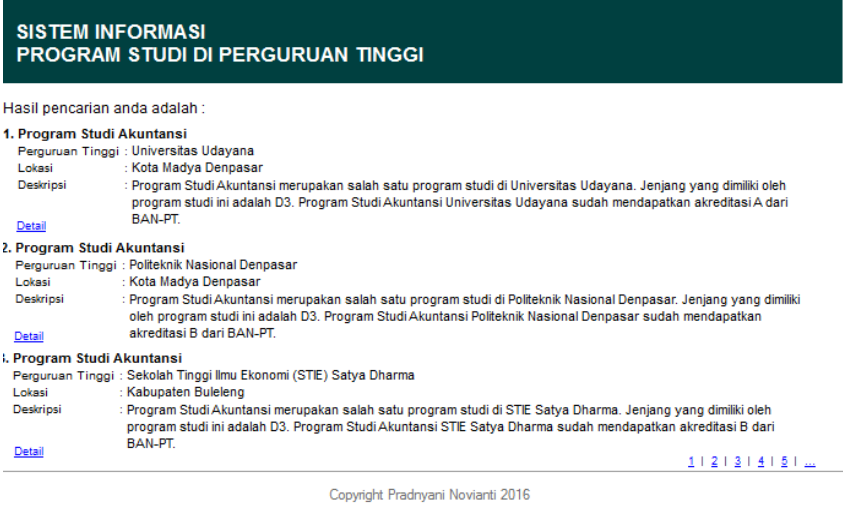

Gambar 9. Hasil Pencarian

SISTEM INFORMASI

PROGRAM STUDI DI PERGURUAN TINGGI

Hasil pencarian anda adalah

1. Program Studi Akuntansi

Perguruan Tinggi : Universitas Udayan

Jalan Sudirman Denpasar

Neg

Program StudiAkuntansi merupakan salah satu program studi di Universitas Udayana. Jenjang yang dimiliki oleh program studi ini adalah D3. Program Studi Akuntansi Universitas Udayana sudah mendapatkan akreditasi $A$ da

Gambar 10. Detail Hasil Pencarian

Nilai recall $(R)$ adalah nilai yang menunjukan tingkat perolehan hasil yang dikembalikan oleh sebuah sistem. Nilai recall $(R)$ diperoleh dengan

Jurnal Sains dan Teknologi | 101 
membandingkan jumlah item relevan yang ditemukan dengan jumlah item relevan yang ada di dalam koleksi sistem. Nilai ini diperoleh seperti pada persamaan (1). Nilai recall yang semakin besar tidak dapat menunjukan suatu sistem baik atau tidak. Nilai recall tertinggi adalah 1 menyatakan bahwa seluruh dokumen dalam koleksi berhasil ditemukan.

$R=\frac{\Sigma_{\text {relevant items retrieved }}}{\text { Total relevant item in ontology }}$

Nilai precision $(\mathrm{P})$ menunjukan tingkat ketepatan sebuah sistem untuk mengembalikan informasi relevan kepada pengguna. Nilai precision $(\mathrm{P})$ diperoleh dengan membandingkan jumlah item relevan yang dikembalikan dengan total jumlah item yang dikembalikan. Nilai ini diperoleh seperti pada persamaan (2-2). Semakin besar nilai precision suatu sistem, maka sistem dapat dikatakan baik. Nilai precision tertinggi adalah 1, yang berarti seluruh dokumen yang ditemukan adalah relevan.

$P=\frac{\Sigma \text { relevant items retrieved }}{\text { Total relevant item retrieved }}$

Hasil pengujian yang diperoleh dapat dilihat pada Tabel 1 dan Tabel 2.

Tabel 1. Pengujian Nilai Recall

\begin{tabular}{|c|c|c|c|c|}
\hline No & Keyword & $\begin{array}{c}\text { Relevant } \\
\text { items } \\
\text { retieved }\end{array}$ & $\begin{array}{c}\text { Total } \\
\text { relevant } \\
\text { item in } \\
\text { antology }\end{array}$ & $R$ \\
\hline 1 & Akuntansi & 10 & 10 & 1 \\
\hline 2 & Arsitektur & 2 & 2 & 1 \\
\hline 3 & Agroteknologi & 3 & 3 & 1 \\
\hline 4 & $\begin{array}{l}\text { Administrasi } \\
\text { Perhotelan }\end{array}$ & 1 & 1 & 1 \\
\hline 5 & Bahasa Inggris & 3 & 4 & 0.75 \\
\hline \multicolumn{4}{|c|}{ Rata-Rata $R$} & 0.95 \\
\hline
\end{tabular}

Hasil pengujian nilai recall (R) menunjukan bahwa nilai $R$ yang diperoleh mendekati 1 yaitu 0,95 . Hal ini menunjukan bahwa sistem sudah mampu menemukan hampir semua jumlah informasi relevan sesuai dengan jumlah informasi relevan yang disimpan di dalam ontologi prodi.

Hasil pengujian nilai precision $(P)$ menunjukan bahwa nilai $P$ yang diperoleh adalah 0.93. Nilai precision yang diperoleh menyatakan bahwa hampir semua informasi relevan dari total keseluruhan informasi relevan telah dikembalikan oleh sistem.

Tabel 2. Pengujian Nilai Precision

\begin{tabular}{llccr}
\hline No & \multicolumn{1}{c}{ Keyword } & $\begin{array}{c}\text { Relevant } \\
\text { items } \\
\text { retieved }\end{array}$ & $\begin{array}{c}\text { Total } \\
\text { relevant } \\
\text { item in } \\
\text { antology }\end{array}$ & $R$ \\
\hline 1 & Akuntansi & 9 & 10 & 0.9 \\
2 & Arsitektur & 2 & 2 & 1 \\
3 & Agroteknologi & 3 & 3 & 1 \\
4 & Administrasi & 1 & 1 & 1 \\
& $\begin{array}{l}\text { Perhotelan } \\
5\end{array}$ & 3 & 4 & 0.75 \\
& Bahasa & 3 & & \\
& Inggris & & & 0.93
\end{tabular}

Menurut hasil pengujian nilai recall dan precision, sistem pencarian prodi memiliki tingkat relevansi yang tinggi. Sistem memiliki efektifitas yang baik, sehingga pengguna dan sistem menginterpretasikan makna yang sama untuk sebuah kata kunci yang diinputkan pada kotak pencarian.

Berdasarkan hasil informasi yang dipaparkan dalam sistem berdasarkan keyword yang diinputkan pengguna, dapat dikatakan bahwa sistem sudah mampu memberikan deskripsi informasi yang baik mengenai program studi dan perguruan 
tinggi yang ingin dicari oleh calon mahasiswa. Sehingga, deskripsi informasi yang dihasilkan oleh sistem dapat menjadi bahan pertimbangan oleh calon mahasiswa untuk memilih program studi pada suatu perguruan tinggi yang diinginkannya.

\section{SIMPULAN}

Sistem pencarian program studi bertujuan untuk membantu calon mahasiswa menemukan informasi terkait dengan program studi yang diinginkan. Sistem pencarian berbasis semantik ini dibangun dan menggunakan ontologi sebagai representasi informasi berbasis pengetahuan. Hal ini dilakukan dengan harapan agar sistem dan pengguna memiliki pemahaman makna yang sama serta informasi program studi memiliki nilai inferensi semantik yang baik. Ontologi sebagai dasar representasi informasi memiliki 4 class, 9 datatype properties dan 4 object properties. Pengujian sistem menggunakan 5 buah kata kunci uji untuk mengetahui tingkat relevansi informasi yang dihasilkan oleh sistem dan hasil yang diperoleh adalah nilai recall sebesar 0.95 dan nilai precision sebesar 0.93 , sehingga dapat dikatakan bahwa sistem memiliki tingkat relevansi yang tinggi ketika mengembalikan informasi yang diinginkan pengguna. Deskripsi informasi yang diberikan oleh sistem dapat digunakan sebagai pertimbangan bagi calon mahasiswa untuk memilih program studi pada perguruan tinggi tertentu.

\section{DAFTAR PUSTAKA}

Abburu, S. (2012). A Survey on Ontology Reasoners and Comparison. International Journal of Computer Applications, 57(17), 33-39.
Atmanti, D. H. (2005). Investasi sumber daya manusia melalui pendidikan. Jurnal Dinamika Pembangunan (JDP), 2(1), 30-39. Retrieved from http://eprints.undip.ac.id/16864/1/Inves tasi_Sumber_Daya_Manusia_Melalui Pendidikan....by_Hastarini_Dwi_Atman ti_(OK).pdf

Berners-lee, T., Hendler, J., \& Lassila, $\mathrm{O}$. (2001). The Semantic Web. Scientific American, 21. doi:10.1007/978-3-64229923-0

Chandrasekaran, B., Josephson, J. R., \& Benjamins, V. R. (1999). What are ontologies, and why do we need them? IEEE Intelligent Systems and Their Applications, 14(1), 20-26. doi:10.1109/5254.747902

Changping, H., \& Yang, Z. (2007). An ontology-based framework for knowledge service in digital library. 2007 International Conference on Wireless Communications, Networking and Mobile Computing, WiCOM 2007, 5340-5343.

doi:10.1109/WICOM.2007.1309

Davies, J., Fensel, D., \& Harmelen, F. van. (2003). Towards The Semantic Web (Ontology-driven Knowledge Management). John Wiley \& Sons Ltd.

Davies, J., Fensel, D., \& van Harmelen, F. (Eds.). (2003). Towards The Semantic Web. England: John Wiley \& Sons Ltd.

Gerber, A., Van Der Merwe, A., \& Barnard, A. (2008). A functional semantic web architecture. Lecture Notes in

Jurnal Sains dan Teknologi | 103 
Computer Science (including Subseries Lecture Notes in Artificial Intelligence and Lecture Notes in Bioinformatics), $5021 \quad$ LNCS, 273-287. doi:10.1007/978-3-540-68234-9_22

Gómez-Pérez, A., Fernández-López, M., \& Corcho, O. (2003). Ontological Engineering with examples from the areas of Knowledge Management, eCommerce and the Semantic Web. Springer.

McGuinness, D. L., \& Harmelen, F. Van. (2003). OWL Web Ontology Language Overview. http://www.w3.org/TR/owlFeatures/, 2004(February), 1-12.

Mehta, A., Makkar, P., Palande, S., \& Wankhede, P. S. B. (2015). Semantic Web Search Engine (SWSE), 4(04), 687-691. Retrieved from http://www.swse.org/

Novianti, K. D. P. (2016). IMPLEMENTASI METHONTOLOGY UNTUK PEMBANGUNAN MODEL. Jurnal TEKNOIF, 4(1), 40-47. Retrieved from https://ejournal.itp.ac.id/index.php/tinfo rmatika/article/view/588/424

Noy, N. F., \& McGuinness, D. L. (2001). Ontology Development 101: AGuide to Creating Your First Ontology. Stanford University.

Noy, N., \& McGuinness, D. (2001). Ontology development 101: A guide to creating your first ontology. Development, 32, 125. doi:10.1016/j.artmed.2004.01.014
Shadbolt, N., Hall, W., \& Berners-Lee, T. (2006). The semantic web revisited. IEEE Intelligent Systems, 21(3), 96101. doi:10.1109/MIS.2006.62

Wahyudi, A. T. (. (2013). SEMANTIC SEARCH PADA DIGITAL LIBRARY ONLINE PUBLIC ACCESS CATALOG. Jurnal Online STMIK EL RAHMA, 1-15. Retrieved from http://jurnal.stmikelrahma.ac.id/assets/f ile/Adhie Tri Wahyudi_stmikelrahma.pdf

Wu-jun, Y., \& Peng, Z. (2010). Study of digital library information retrieval model based on ontology. Computer Application and System Modeling (ICCASM), 2010 International Conference on, 10(Iccasm), 203-206. doi:10.1109/ICCASM.2010.5622829 